\title{
THE MANAGEMENT OF CONGENITAL TALIPES
}

\author{
A. Graham Apley, F.R.C.S. \\ Consultant Orthopaedic Surgeon, \\ Rowley Bristow Hospital, Pyrford, Surrey.
}

IT HAS long been realised that there are two varieties of talipes: calcaneo-valgus, in which the foot is held dorsiflexed and everted; and equinovarus, in which the foot is held plantarflexed, inverted and adducted.

Although calcaneo-valgus is the commoner, it is less serious because it is readily corrected within a few weeks by simple stretching. Its importance lies in the occasional association with congenital hip dislocation in the same limb, a condition which must always be excluded by clinical examination (using Barlow's or Ortolani's test) and, if necessary, by X-ray.

Equino-varus is muoh more serious and is liable to lead to progressively severe deformity. But, as recently pointed out by Attenborough (1966), there are, in fact, two clinically distinct varieties of equino-varus with markedly different prognoses: (1) "Easy" in which the deformity is readily correctible by simple manipulation, is easily held by strapping, and once overcorrected does not tend to recur; this variety is probably due to mal-position for a short period of intraulterine life:(2) "Resistant" in which the correction is harder to achieve and in which, even if apparent overcorrection is obtained and held for many months by strapping or splints, recurrence of deformity is liable to occur and to require operative treatment. This variety may well be associated with fibrosis of muscle and possibly results from immobilisation of joints during embryonic development, though a genetic factor almost certainly co-exists.

\section{Orthodox Treatment of Equino-varus}

(1) There is no doubt that the earlier treatment is begun the better-ideally within the first 24 hours. The foot is manipulated without anaesthetic and is held by strapping. At successive manipulations (usually weekly) further correction is obtained until the foot is held in calcaneus, valgus and abduction. Manipulation and strapping are continued until the child holds the foot naturally in this overcorrected position, and usually until standing begins. Intermittent splintage with Denis Browne splints or some modification of them is ihen used and the child is examined at intervals for recurrence of the deformity.
(2) When treatment has not been started so early, or overcorrection has proved impossible, the foot may be manipulated under anaesthetic and held in plaster. At weekly intervals the plaster is wedged in such a way as to overcorrect one deformity at a time (Kite, 1935) and the plaster is continued for many months.

(3) When treatment has not been started until the child begins to stand, or the deformity has recurred late despite early treatment, operation is necessary. The usual method is to elongate the tendo achillis and to divide the contracted soft tissues on the inner side of the foot (Brockmann, 1930; Perkins, 1961), subsequently holding the foot overcorrected in plaster for six months.

(4) At a still later stage (age 5 years or more) soft-tissue operations must be supplemented by bone carpentry. The operations used include excision of part of the calcaneo-cuboid joint (Evans, 1961), osteoltomy of the os calcis (Dwyer, 1963) and wedge tarsectomy. These procedures may enable the foot to be placed flat on the ground, but they do not produce a foot of normal size, shape and suppleness.

\section{Towards The Future}

The "easy" cases present no problem. In resistant cases, however, it is surely illogical to await failure of closed methods before embarking upon surgical correction. Such delay contravenes a cardinal surgical principle-the earlier a congenital deformity is corrected the better. With delay secondary adaptive changes in the bones and joints are inevitable, and inevitably the ultimate result is jeopardised.

Surgery in the first few weeks of life is much more likely to be successful but, unless many unnecessary operations are to be performed, we must be able to recognise the potentially resistant cases. It seems likely that failure of simple closed methods can, in fact, be predicted: if the calf is thin, the heel small and high, and correction beyond the neutral position not obtainable within three weeks of beginning manipulation, then failure is likely.

It is almost certainly along these lines that future techniques will develop. For example we at Pyrford (and Helal at Enfield) have been trying the following routine. The foot of the new- 
born baby is manipulated and strapped at weekly intervals for three weeks. If the shape is then satisfactory and overcorrection has been obttained, this method is continued and it is usually found that only a few weeks of further strapping is needed. But if at three weeks the shape or correction is unsatisfactory, operation is performed-and we feel it should not be delayed beyond the age of 4-6 weeks.

Through a medial incision the tendo achillis is elongated. The foot invertors and plantar flexors are then inspected and if any muscle is short and fibrous its tendon is elongated. In the few cases operated on before the age of six weeks we have so far not needed to elongate any structures other than the tendo achillis and tibialis posterior in order to obtain overcorrection without force; but in one case at 10 weeks the posterior capsule of the ankle also required division.

Following operation the foot is held overcorrected in plaster for six weeks, after which all splintage is discarded. The results so far have been extremely encouraging and the method has the obvious advantage that operation and splintage are over and done with long before the child is beginning to stand or walk.

With further experience we may well find that even in the early cases elongation of only the tendo achillis and tibialis posterior is not always sufficient. Attenborough (1966), for example, in his excellent account of the early treatment also implicates other structures. Although he does not advocate operation until the age of 6-9 weeks he has demonstrated contracture of the long toe flexors and of the posterior capsule of the ankle $\frac{0}{2}$ joint in dissections of still-born infants. Denham $气$ (1966), another advocate of early operation, 3 elongates the tendo achillis and divides the plantar $\stackrel{\mathbb{Q}}{\varrho}$ fascia, on the assumption that contracture of $c$. these structures (which constitute a single $\vec{F}$ morphological sheet interrupted by the os calcis) $\stackrel{\vec{P}}{+}$ is the primary fault. Other writers (e.g. Irani ando Sherman, 1963) have maintained that the primary 음 anomaly is in the talus itself.

There may well be different varieties of resistant $\stackrel{\vec{D}}{\overrightarrow{0}}$ talipes equino-varus and, although the invertors and plantar flexors are undoubtedly of major im- $\omega$ portance, it would be unwise in the present state $\overrightarrow{0}$ of our knowledge to assume that they alone are at fault. In any event there is no need for fixed $\vec{\omega}$ pre-conceived notions of pathology-the dissec- $\stackrel{\Omega}{\circ}$ tion should proceed until overcorrection is $\stackrel{\circ}{2}$ obtained without force. The important point is 3 . to operate early, at a stage when simple soft-tissue $\vec{i}$ procedures should prove sufficient and offer the best hope of restoring the foot to normal shape and suppleness.

REFERENCES
AtTenborough, C. G. (1966): J. Bone Jt. Surg., 48B, 1,31 .

BrockmanN, E. P. (1930): Congenital Club Foot. Bristol: John Wright.

DenhaM, R. A. (1966): Personal Communication.

DWYER, F. C. (1963): J. Bone Jt. Surg., 45B, 1, 67. EVANS, D. (1961): J. Bone Jt. Surg., 43B, 4, 722. 8 Helal, B. (1966): Personal Communication.

IrANI, R. N., and Sherman, M. S. (1963): J. Bone Surg., 45A, 1, 45.

KITE, J. H. (1935): Surg. Gynec. Obstet, 61, 190.

PERKINS, O. (1961) Orthopaedics. London: Athlone Press.

\title{
MUMPS
}

\author{
R. T. EMOND, M.B., M.R.C.P., D.T.M. \& H.
}

Physician Superintendent, Coppetts Wood Hospital, London, N.10.

\begin{abstract}
Aetiology
The virus of mumps is readily isolated by inoculation of the yolk sac or amniotic cavity of the chick embryo but tissue culture, using monkey kidney, human amnion or HeLa carcinoma cell lines is more sensitive. Mumps virus varies in size from $90-135 \mathrm{~m} \mu$. It is composed of RNA and has an internal helical structure characteristic of the myxovirus group to which it belongs.

Mumps virus has been isolated from saliva, urine and cerebrospinal fluid for six days before the onset of symptoms and for thirteen days after. In children with sub-clinical infections, the virus has bern isolated during the corresponding period
\end{abstract}

after exposure. Isolations have been made from $D$ the blood on the first day of illness. During the later stages of mumps, the virus is most readily $N$ cultured from urine.

\section{Epidemiology}

Mumps is endemic in most urban communities throughout the world. Epidemics appear at irregular intervals of 7-8 years and are often $\stackrel{0}{=}$ associated with overcrowding. The main incidence $\cong$ of clinical mumps occurs in the age groups 5-15: years. By adult life, $60 \%$ give a history of having had mumps. Serological tests, however, show a much greater incidence of mumps so it would 